\title{
Antifungal Susceptibility Pattern of Non - Dermatophytic Fungi Causing Onychomycosis
}

\author{
Kaushal A', Gahalaut P², Goyal RK³, Agarwal N, Mishra N², Rastogi MK ${ }^{5}$ \\ ${ }^{1}$ Consultant Dermatologist, Faizabad, ${ }^{2}$ Professor, Department of Dermatology, ${ }^{3}$ Professor, Department of Microbiology, \\ ${ }^{4}$ Senior Resident, ${ }^{5}$ Associate Professor, Department of Dermatology, Shri Ram Murti Smarak Institute of Medical \\ Sciences, Bareilly, India.
}

\begin{abstract}
Introduction: Non-dermatophytic molds (NDM) are filamentous fungi or yeast, commonly found in nature as saprophytes and plant pathogens. The incidence of onychomycosis due to NDM is $1.45-16.6 \%$. NDMs are usually resistant to conventional antifungal treatment.

Objective: To know the anti-fungal susceptibility pattern of non-dermatophyte fungi causing onychomycosis.

Materials and Methods: A prospective hospital based cross-sectional study was done on non - dermatophytic isolates from patients with clinical suspicion of onychomycosis. All non - dermatophytic isolates were subjected to anti-fungal susceptibility against terbinafine, itraconazole, fluconazole and griseofulvin by micro broth dilution method.

Results: NDM were isolated in $\mathbf{2 0 . 2 \%}$ cases of clinically suspected onychomycosis, among which Fusarium species was the most common followed by Aspergillus species and Candida species. MIC50 (Mean Inhibitory Concentration) for overall non - dermatophytic isolates for terbinafine, itraconazole, fluconazole and griseofulvin was $0.25 \mu \mathrm{g} / \mathrm{mL}, 0.5 \mu \mathrm{g} /$ $\mathrm{mL}, 32 \mu \mathrm{g} / \mathrm{mL}$ and $2 \mu \mathrm{g} / \mathrm{mL}$ respectively and the order of sensitivity was Itraconazole $(74.7 \%)>$ terbinafine $(68 \%)>$ Fluconazole $(60 \%)>$ Griseofulvin (51.6\%) of the study samples. For Fusarium species, the -sensitivity for terbinafine was $(73.5 \%)>$ itraconazole $(67.6 \%)>$ fluconazole $(64.7 \%)$ and griseofulvin (64.7\%). For Aspergillus species, the sensitivity for itraconazole was $79.1 \%>$ fluconazole $(58.3 \%)>$ terbinafine $(54.1 \%)>$ griseofulvin $(50 \%)$. For Candida species, the sensitivity was fluconazole $(83.3 \%)>$ itraconazole $(75 \%)>$ terbinafine $(41.6 \%)$, while no candida species was found sensitive to griseofulvin.
\end{abstract}

Conclusion: Non-dermatophytes play a significant role in onychomycosis. On in vitro estimation, Itraconazole was the most sensitive drug, followed by terbinafine, fluconazole and griseofulvin.

Key words: Antifungal Agents; Fluconazole; Itraconazole; Onychomycosis; Terbinafine

\section{Introduction}

$\mathrm{O}$ nychomycosis is a fungal infection of nails caused by dermatophytes, yeasts, and nondermatophytic molds. ${ }^{1}$ For all the culture positive cases of onychomycosis, dermatophytes account for nearly $70 \%$, non dermatophytic molds account for $1.45-16.60 \%$ and yeast account for $1-31 \%$ of the cases. ${ }^{1,2}$ Few studies have shown a very high number of non - dermatophytes i.e. upto $68 \%$ of culture positive case of onychomycosis, it can be due to improved

Financial disclosure: None.

Conflict of interest to disclosure: None declared.

Address of Correspondence

Dr. Madhur Kant Rastogi

Associate Professor

Department of Dermatology, Venereology \& Leprosy

Shri Ram Murti Smarak Institute of Medical Sciences, Bareilly

E-mail:kantmadhur@gmail.com diagnostic techniques and increased awareness of non dermatophytic fungi as potential etiologic agents. ${ }^{3,4}$ While non-dermatophytic onychomycosis respond to oral or topical antifungal therapy, poor or incomplete response might still be seen in some patients. ${ }^{2,4}$

Submitted: $6^{\text {th }}$ January 2020

Accepted: $3^{\text {rd }}$ February 2020

Published: $7^{\text {th }}$ October 2020

How to cite this article

Kaushal A, Gahalaut P, Goyal RK, Agarwal N, Mishra N, Rastogi MK. Antifungal susceptibility pattern of non - dermatophytic fungi causing onychomycosis. Nepal Journal of Dermatology Venereology and Leprology 2020;18(1):28-36. https://doi. org/10.3126/njdvl.v18i1.27120.

\section{(c) (i)}

Licensed under CC BY 4.0 International License which permits use, distribution and reproduction in any medium, provided the original work is properly cited. 
Resistance to anti-fungal drugs is a growing health crisis, fueled by widespread injudicious use of various antifungal drugs, which may be responsible for treatment failure. Hence, the targeted Antifungal therapy for the non- dermatophytic onychomycosis is of utmost importance. ${ }^{5}$

In vitro antifungal susceptibility tests are now mainly used for epidemiological surveys, determination of the degree of antifungal activity, and the prediction of clinical outcome based upon an optimization of antifungal therapy. ${ }^{5}$ The data regarding the sensitivity pattern of various anti-fungals to NDM is scarce. Hence this study was conducted to determine the in vitro susceptibility of non dermatophytic fungi causing onychomycosis to Terbinafine, Fluconazole, Itraconazole, and Grieseofulvin by Broth microdilution technique.

Material and Methods - After obtaining ethical clearance from the Institutional Ethics Committee, nondermatophytic isolates on culture from the clinically suspected cases of onychomycosis, presenting to the Department of Dermatology, Shri Ram Murti Smarak Institute of Medical Sciences, Bhojipura, Bareilly from Nov 2016 to May 2018 were included. Further processing \& anti fungal sensitivity study was done in Department of Microbiology. Figure.1 describes the study design.

For consideration of non-dermatophytes as a pathogen, three out of six criteria should be chosen. ${ }^{4}$ The criteria taken in our study were-

1. Culture positivity for non dermatophytes

2. Absence of Dermatophytes in culture

3. Repeated isolation of the non dermatophytic molds on two separate occasions done on 2 to 4 weeks

Aspergillus niger ATCC 6275 and Candida albicans ATCC 10231 were used as quality control organisms.

Broth microdilution method - The CLSI M38-A2\& M27-A3 guidelines were followed. The test was performed in microtiter plates with RPMI-1640 without bicarbonate and buffered to $\mathrm{pH} 7.0$ with 3 [N-morpholino] propane sulfonic acid (MOPS) ${ }^{6,7}$ For each drug six dilutions were used. Hundred microlitre of two fold drug dilutions were placed in wells with a multichannel pipette to yield twice the final strength required for the test i.e. $4-128 \mu \mathrm{g} / \mathrm{ml}$ for fluconazole, $0.25-8 \mu \mathrm{g} / \mathrm{ml}$ for griseofulvin, $0.125-4.0 \mu \mathrm{g} / \mathrm{ml}$ for itraconazole, and $0.015-0.50 \mu \mathrm{g} / \mathrm{ml}$ for terbinafine.
Stock solutions were prepared by dissolving the anti fungal powder in their specific solvent. Fluconazole was dissolved in distilled water in concentration of 1280 $\mu \mathrm{g} / \mathrm{ml}$, itraconazole in DMSO (Dimethyl sulfoxide) 400 $\mu \mathrm{g} / \mathrm{ml}$, terbinafine in DMSO $0.4 \mu \mathrm{g} / \mathrm{ml}$ and griseofulvin in DMSO $800 \mu \mathrm{g} / \mathrm{ml}$.

Inoculum suspension of the fungi were prepared from 7-10 day old culture grown on PDA (Phosphate Dextrose Agar) at $28^{\circ} \mathrm{C}^{\circ}$ in a BOD (Biological Oxygen Demand) incubator. The resulting mixture of 0.5 mcfarland turbidity $\left(0.5 \times 10^{4}-5.0 \times 10^{4}\right.$ spores/hyphae per $\mathrm{ml}$ ) dilution of every isolated strain was made.

All the tests were performed in sterile, flat-bottomed, 96-well micro plates. For performing the susceptibility testing $100 \mu \mathrm{l}$ of the RPMI 1640, was mixed with 100 $\mu l$ antifungal drug inoculate in first well and total of six dilutions were prepared.

Then $100 \mu \mathrm{l}$ of the diluted inoculums suspension was added and brought the final dilution of drugs to $2.0-64.0 \mu \mathrm{g} / \mathrm{ml}$ for fluconazole, $0.125-4.0 \mu \mathrm{g} / \mathrm{ml}$ for griseofulvin, $0.062-2.0 \mu \mathrm{g} / \mathrm{ml}$ for itraconazole, and $0.015-0.5 \mu \mathrm{g} / \mathrm{ml}$ for terbinafine. The micro titer plate contents were incubated at $28^{\circ} \mathrm{C}$, by avoiding desiccation of the wells and were read visually with the aid of an inverted mirror after 7 days of incubation. The range, GM Geometic Mean), MIC 50 (Minimum inhibitory concentration required to inhibit the growth of $50 \%$ of organisms) and MIC90 (Minimum inhibitory concentration required to inhibit the growth of $90 \%$ of organisms) were determined for various isolated fungi.

Since, there is no established breakpoint for antifungals for non dermatophytes, MIC50 was assumed as a breakpoint. The strains showing the MIC value equal to or less than the MIC50 was considered sensitive and strains showing MIC value more than MIC50 was considered resistant.

\section{Results}

Total 470 patients were included in study, culture was positive in 276 patients, out of which 181 were dermatophytes and were excluded from the study while 95) non- dermatophytes were isolated (Figure1. Among the non - dermatophytic isolates, the most common genra was Fusarium species in 34/95 i.e. 35.8\% followed by Aspergillus species 24/95i.e. 25.3\% and Candida species in 12/95 i.e $12.6 \%$ cases. Table 1 shows the number and the percentage of isolated non -dermatophytes. 
The susceptibility patterns for the fungal isolates are tabulated in Table 2. In our study the MIC50 for various non-dermatophyte isolates for terbinafine, itraconazole, fluconazole and griseofulvin were $0.25 \mu \mathrm{g} /$ $\mathrm{mL}, 0.5 \mu \mathrm{g} / \mathrm{mL}, 32 \mu \mathrm{g} / \mathrm{mL}$ and $2 \mu \mathrm{g} / \mathrm{m}$, respectively. And MIC ranges were $0.03->0.5 \mu \mathrm{g} / \mathrm{mL}, 0.062->2 \mu \mathrm{g} /$ $\mathrm{mL}, 2->64 \mu \mathrm{g} / \mathrm{mL}$ and $0.125->4 \mu \mathrm{g} / \mathrm{mL}$, respectively, indicating that some isolates were resistant in vitro.

Table 3 shows the range, MIC50 and MIC90 of isolated non dermatophytes against the four drugs. The GM of MIC for fusarium species for terbinafine, itraconazole, fluconazole and griseofulvin were $0.24 \mu \mathrm{g} / \mathrm{mL}, 0.63 \mu \mathrm{g} /$ $\mathrm{mL}, 29 \mu \mathrm{g} / \mathrm{mL}$ and $2.1 \mu \mathrm{g} / \mathrm{mL}$, respectively. The Figure 4 shows the percentage of sensitive and resistant isolates against various antifungal drugs.
Since the breakpoint was determined on MIC50, on further analysis, Fusarium species had maximum sensitivity in vitro to terbinafine (73.5\%) followed by itraconazole (67.6\%), fluconazole (64.7\%) and griseofulvin (64.7\%). For Aspergillus species, maximum sensitivity was seen to itraconazole (79.1\%), followed by fluconazole $(58.3 \%)$, then terbinafine (54.1\%) least to griseofulvin (50\%). For Candida species, the maximum sensitivity was observed to fluconazole (83.3\%), followed by itraconazole (75\%) and terbinafine $(41.6 \%)$, resistance in vitro was observed to griseofulvin. The percentages of sensitive isolates of various non dermatophytes according to the assumed breakpoint are tabulated in Table 4.

Patients presenting in dermatology OPD with nail involvement $(n=1200)$

Nail samples from suspected case of onychomycosis were taken

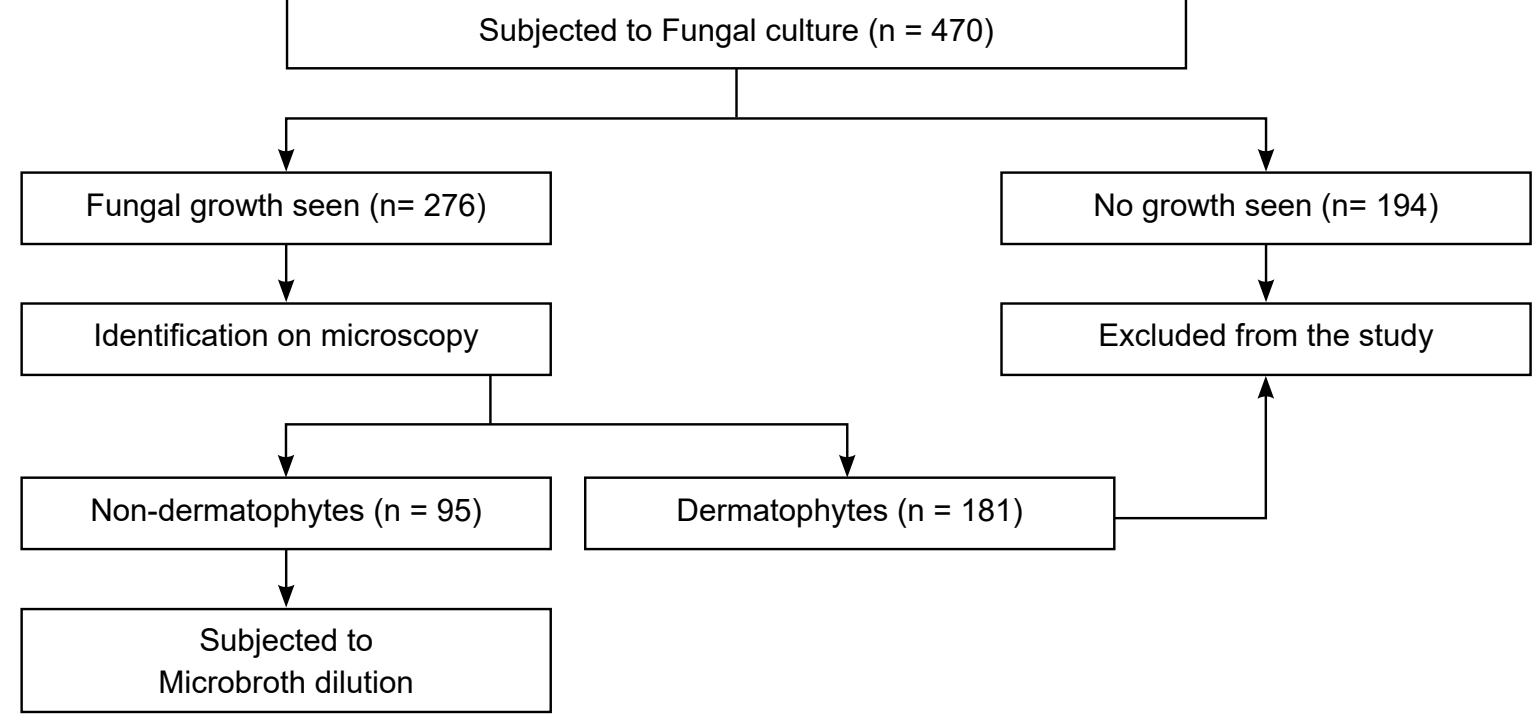

Figure 1: Study Design

Table 1: Number \& percentage of fungal isolates

\begin{tabular}{|c|c|c|}
\hline Species & Number & Percentage \\
\hline Fusarium & 34 & 35.8 \\
\hline Aspergillus & 24 & 25.3 \\
\hline Candida & 12 & 12.6 \\
\hline Neoscytalidium & 6 & 6.3 \\
\hline Rhizopus & 6 & 6.3 \\
\hline Alternaria & 5 & 5.3 \\
\hline Penicillium & 4 & 4.2 \\
\hline Bipolaris & 2 & 2.1 \\
\hline Curvularia & 2 & 2.1 \\
\hline
\end{tabular}


Table 2: Antifungal susceptibility pattern of NDMs against 4 antifungal drugs

\begin{tabular}{|c|c|c|c|c|}
\hline & $\begin{array}{c}\text { Itraconazole } \\
\text { (in } \mu \mathrm{g} / \mathrm{ml})\end{array}$ & $\begin{array}{c}\text { Terbinafine } \\
\text { (in } \mu \mathrm{g} / \mathrm{ml})\end{array}$ & $\begin{array}{c}\text { Fluconazole } \\
\text { (in } \mu \mathrm{g} / \mathrm{ml})\end{array}$ & $\begin{array}{c}\text { Griseofulvin } \\
\text { (in } \mu \mathrm{g} / \mathrm{ml} \text { ) }\end{array}$ \\
\hline GM & 0.57 & 0.27 & 32.85 & 2.45 \\
\hline MIC50 & 0.5 & 0.25 & 32 & 2 \\
\hline MIC90 & 1 & 0.5 & $>64$ & $>4$ \\
\hline Range & $0.062->2$ & $0.03->0.5$ & $2->64$ & $0.125->4$ \\
\hline
\end{tabular}

Table 3: Susceptibility Pattern of Fungal Isolates (Values in $\mu \mathrm{g} / \mathrm{ml}$ )

\begin{tabular}{|c|c|c|c|c|c|}
\hline Species & Drug & Range & GM & MIC 50 & MIC 90 \\
\hline \multirow{4}{*}{$\begin{array}{l}\text { Fusarium } \\
\qquad(n=34)\end{array}$} & Terbinafine & $0.06->0.5$ & 0.24 & 0.25 & 0.5 \\
\hline & Itraconazole & $0.062->1$ & 0.63 & 0.5 & 1 \\
\hline & Fluconazole & $2->64$ & 29 & 32 & $>64$ \\
\hline & Griseofulvin & $0.125-4$ & 2.1 & 2 & 4 \\
\hline \multirow{4}{*}{$\begin{array}{l}\text { Aspergillus } \\
\quad(n=24)\end{array}$} & Terbinafine & $0.125->0.5$ & 0.31 & 0.25 & $>0.5$ \\
\hline & Itraconazole & $0.5->1$ & 0.59 & 0.5 & 1 \\
\hline & Fluconazole & $16->64$ & 36.7 & 32 & $>64$ \\
\hline & Griseofulvin & $1->4$ & 2.75 & 2 & $>4$ \\
\hline \multirow{4}{*}{$\begin{array}{l}\text { Candida } \\
(n=12)\end{array}$} & Terbinafine & $0.25->0.5$ & 0.39 & 0.5 & 0.5 \\
\hline & Itraconazole & $0.25-1$ & 0.46 & 0.5 & 0.5 \\
\hline & Fluconazole & $8->64$ & 31.27 & 32 & 64 \\
\hline & Griseofulvin & $4->4$ & 4 & $>4$ & $>4$ \\
\hline \multirow{4}{*}{$\begin{array}{l}\text { Rhizopus } \\
\qquad(n=6)\end{array}$} & Terbinafine & $0.03-0.25$ & 0.175 & 0.18 & NC \\
\hline & Itraconazole & $0.5->2$ & 0.5 & 1 & NC \\
\hline & Fluconazole & $64->64$ & 64 & 64 & NC \\
\hline & Griseofulvin & $2-4$ & 3 & 2 & NC \\
\hline \multirow{4}{*}{$\begin{array}{l}\text { Neoscytalidium } \\
\qquad(n=6)\end{array}$} & Terbinafine & $0.125->0.5$ & 0.38 & 0.5 & NC \\
\hline & Itraconazole & $0.25->2$ & 0.65 & 0.5 & NC \\
\hline & Fluconazole & $>64->64$ & $>64$ & $>64$ & NC \\
\hline & Griseofulvin & $2-4$ & 3.67 & 4 & NC \\
\hline \multirow{4}{*}{$\begin{array}{l}\text { Alternaria } \\
\qquad(n=5)\end{array}$} & Terbinafine & $0.125-0.25$ & 0.175 & 0.125 & NC \\
\hline & Itraconazole & $0.5-0.5$ & 0.5 & 0.5 & NC \\
\hline & Fluconazole & $16-32$ & 28.8 & 32 & NC \\
\hline & Griseofulvin & $1-2$ & 1.6 & 2 & NC \\
\hline \multirow{4}{*}{$\begin{array}{l}\text { Penicillium } \\
(n=4)\end{array}$} & Terbinafine & $0.25-0.25$ & 0.25 & 0.25 & NC \\
\hline & Itraconazole & $0.5-1$ & 0.63 & 0.5 & NC \\
\hline & Fluconazole & $32->64$ & 42.67 & 32 & NC \\
\hline & Griseofulvin & $1-1$ & 1 & 1 & NC \\
\hline \multirow{4}{*}{$\begin{array}{l}\text { Bipolaris } \\
\qquad(n=2)\end{array}$} & Terbinafine & $0.125-0.125$ & 0.125 & NC & NC \\
\hline & Itraconazole & $0.5-0.5$ & 0.5 & NC & NC \\
\hline & Fluconazole & $32-64$ & 48 & NC & NC \\
\hline & Griseofulvin & $2-4$ & 3 & NC & NC \\
\hline \multirow{4}{*}{$\begin{array}{l}\text { Curvularia } \\
\qquad(n=2)\end{array}$} & Terbinafine & $0.25-0.25$ & 0.25 & NC & NC \\
\hline & Itraconazole & $0.5-0.5$ & 0.5 & NC & NC \\
\hline & Fluconazole & $32->64$ & $\mathrm{~N} / \mathrm{A}$ & NC & NC \\
\hline & Griseofulvin & $2-2$ & 2 & NC & NC \\
\hline
\end{tabular}

NC-Not calculated. ${ }^{*}$ MIC 90 not calculated because of the smaller sample size (i.e. $<10$ strains in each category). 
Table 4: Sensitivity pattern of isolates (values in percentage)

\begin{tabular}{|c|c|c|c|c|}
\hline Species & Terbinafine (\%) & $\begin{array}{c}\text { Itraconazole } \\
\text { (\%) }\end{array}$ & $\begin{array}{c}\text { Fluconazole } \\
\text { (\%) }\end{array}$ & $\begin{array}{c}\text { Griseofulvin } \\
\text { (\%) }\end{array}$ \\
\hline Fusarium & 73.5 & 67.6 & 64.7 & 64.7 \\
\hline Aspergillus & 54.1 & 79.1 & 58.3 & 50 \\
\hline Candida & 41.6 & 75 & 83.3 & 0 \\
\hline Rhizopus & 100 & 33.3 & 0 & 16.6 \\
\hline Neoscytalidium & 66.6 & 50 & 0 & 100 \\
\hline Alternaria & 100 & 100 & 100 & 100 \\
\hline Penicillium & 100 & 75 & 50 & 50 \\
\hline Bipolaris & 100 & 100 & 50 & 100 \\
\hline Curvularia & 100 & 100 & 50 & \\
\hline
\end{tabular}

Table 5: Comparison of isolation rates of NDMs with the previous Indian studies

\begin{tabular}{|c|c|c|c|c|c|c|c|}
\hline Studies & Kaur et $\mathrm{al}^{8}$ & Grover et al ${ }^{9}$ & Lone et $\mathrm{al}^{10}$ & $\begin{array}{c}\text { Lakshmanan } \\
\text { et } \mathrm{al}^{11}\end{array}$ & Kaur et al ${ }^{12}$ & $\begin{array}{c}\text { Jesudanam et } \\
\mathrm{al}^{13}\end{array}$ & $\begin{array}{c}\text { Present } \\
\text { study }\end{array}$ \\
\hline YEAR & $2013-2014$ & 1999-2001 & $2010-11$ & 2011-12 & $2000-05$ & 1998-99 & 2016-19 \\
\hline PLACE & $\begin{array}{c}\text { New Delhi } \\
\text { (North india) }\end{array}$ & $\begin{array}{l}\text { (North East } \\
\text { India) }\end{array}$ & $\begin{array}{c}\text { Kashmir } \\
\text { (North india) }\end{array}$ & $\begin{array}{l}\text { Tamil nadu } \\
\text { (South India) }\end{array}$ & $\begin{array}{c}\text { New Delhi } \\
\text { (North India) }\end{array}$ & Vishkapatnam & $\begin{array}{c}\text { Bareilly } \\
\text { (North India) }\end{array}$ \\
\hline $\begin{array}{l}\text { Isolation } \\
\text { rates }\end{array}$ & $55 \%$ & $34 \%$ & $31.6 \%$ & $24.4 \%$ & $4.4 \%$ & $3.5 \%$ & $34.4 \%$ \\
\hline
\end{tabular}

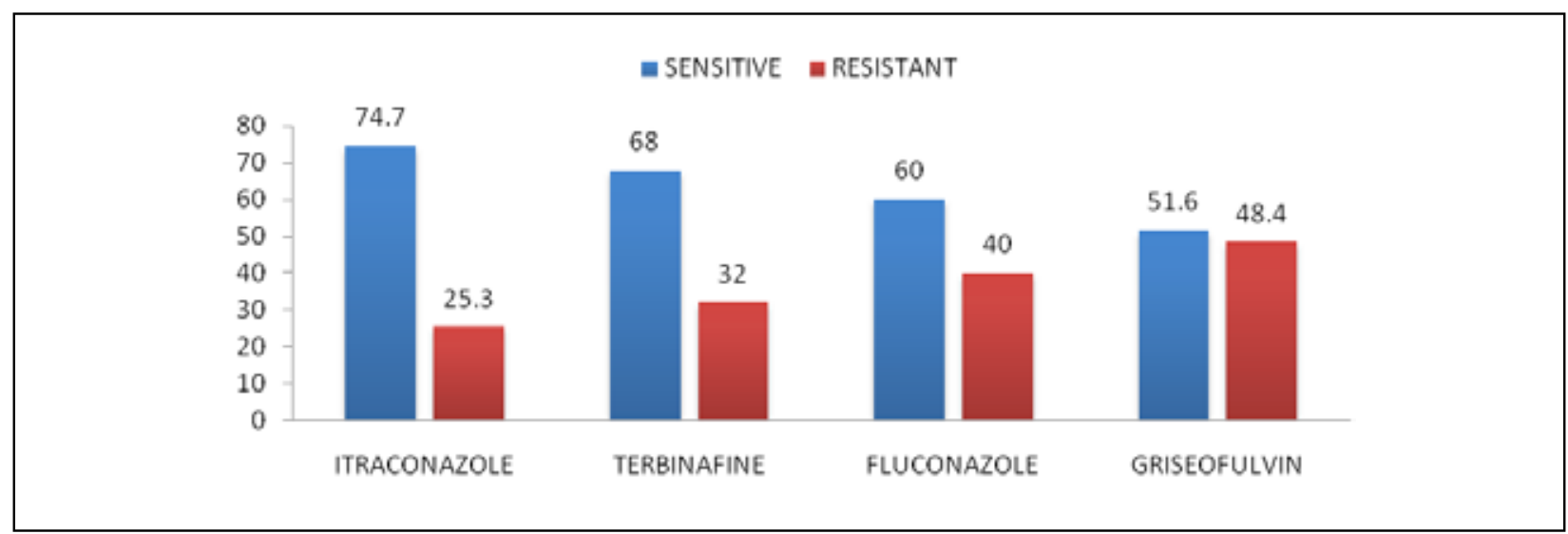

Figure 2: Percentage of sensitive and resistant non-dermatophytic fungal isolates against various antifungal drugs

\section{Discussion}

In the present study, the isolation rate of the fungus from the suspected cases of onychomycosis was $58.7 \%$, out of all the fungal isolates $34.4 \%$ were nondermatophytes. The isolation rates in the previous studies conducted from various parts of India are given in Table 5. This variation in the isolation rate can be attributed to varied climatic or geographic differences \& incomplete antifungal treatment. This table also helps us conclude that there is rise in NDMs.

In the present study, Fusarium species comprised 35\% of NDMs isolated followed by Aspergillus species in $25 \%$ of NDMs and Candida species was seen in $12 \%$ cases. This is in contrast to studies by Attal et al, BassiriJahromi et al, and Adhikari et al who have shown Aspergillus species more common than Fusarium species. ${ }^{14-16}$ While according to Biradar et al, Fusarium species was most commonly isolated followed by Aspergillus species. ${ }^{17}$

For non - dermatophytes, the order of in-vitro activity was terbinafine (GM - $0.27 \mu \mathrm{g} / \mathrm{mL})>$ itraconazole $(\mathrm{GM}-0.57 \mu \mathrm{g} / \mathrm{mL})>$ griseofulvin $(\mathrm{GM}-2.45 \mu \mathrm{g} / \mathrm{mL})>$ fluconazole (GM - $32.85 \mu \mathrm{g} / \mathrm{mL}$ ). This results were in concordance with the study by Gupta et al where the order of in vitro activity was terbinafine $>$ itraconazole > fluconazole. ${ }^{18}$ In same study by Gupta et al, MIC range, MIC50 and MIC 90 of non- dermatophytes for 
itraconazole was $0.06->8 \mu \mathrm{g} / \mathrm{mL}, 4 \mu \mathrm{g} / \mathrm{mL}$ and $>8 \mu \mathrm{g} /$ $\mathrm{mL}$, for terbinafine it was $0.06->2 \mu \mathrm{g} / \mathrm{mL}, 2 \mu \mathrm{g} / \mathrm{mL}$, $>2 \mu \mathrm{g} / \mathrm{mL}$ and for fluconazole, 1 - $>64 \mu \mathrm{g} / \mathrm{mL}, 64 \mu \mathrm{g} / \mathrm{mL}$ and $>64 \mu \mathrm{g} / \mathrm{mL}$, respectively. ${ }^{18}$ Biancalana et al also concluded that for NDM, the MIC range and median for terbinafine was $0.008-4.10 \mu \mathrm{g} / \mathrm{mL}$ and $2.05 \mu \mathrm{g} /$ $\mathrm{mL}$ and for itraconazole was $0.05-8.0 \mu \mathrm{g} / \mathrm{mL}$ and $0.25 \mu \mathrm{g} / \mathrm{mL} .{ }^{19}$ In the past study of Garcia-Effron et al, terbinafine exhibited a good activity in vitro with a geometric mean (GM) of MICs of $1.57 \mu \mathrm{g} / \mathrm{mL}$. However, MIC values ranged between 0.03 and $>16 \mu \mathrm{g} / \mathrm{mL}^{20}$

According to the present study, in case of Fusarium species, the mean MIC of terbinafine, itraconazole, fluconazole and griseofulvin was $0.24 \mu \mathrm{g} / \mathrm{mL}, 0.63 \mu \mathrm{g} /$ $\mathrm{mL}, 29 \mu \mathrm{g} / \mathrm{mL}$ and $2.1 \mu \mathrm{g} / \mathrm{mL}$, respectively. According to Ghannoum et al, for Fusarium species, the mean MIC of terbinafine, itraconazole, fluconazole and griseofulvin were $>16 \mu \mathrm{g} / \mathrm{mL}, 6 \mu \mathrm{g} / \mathrm{mL},>64 \mu \mathrm{g} / \mathrm{mL}$ and $64 \mu \mathrm{g} / \mathrm{mL}$, respectively. ${ }^{21}$ In a study by Alastruey - Izquierdo et al, for MIC range for terbinafine and itraconazole was $0.25-32 \mu \mathrm{g} / \mathrm{mL}$ and $1-16 \mu \mathrm{g} / \mathrm{mL}$, respectively. ${ }^{22}$

In our study, for Aspergillus species, the mean MIC of terbinafine, itraconazole, fluconazole and griseofulvin was $0.31 \mu \mathrm{g} / \mathrm{mL}, 0.59 \mu \mathrm{g} / \mathrm{mL}, 36.7 \mu \mathrm{g} / \mathrm{mL}$ and $2.75 \mu \mathrm{g} /$ $\mathrm{mL}$. respectively. Ghannoum et al reported that for Aspergillus species, the mean MIC of terbinafine, itraconazole, fluconazole and griseofulvin was $0.53 \mu \mathrm{g} / \mathrm{mL}, 0.375 \mu \mathrm{g} / \mathrm{mL},>64 \mu \mathrm{g} / \mathrm{mL}$ and $>64 \mu \mathrm{g} / \mathrm{mL}$, resepectively. ${ }^{21}$ In a past study by Lalitha et al, the MIC 50 of itraconazole for overall NDM, Aspergillus species and Fusarium species was $0.5 \mu \mathrm{g} / \mathrm{mL}, 0.125 \mu \mathrm{g} / \mathrm{mL}$ and $>8 \mu \mathrm{g} / \mathrm{mL}$, respectively. ${ }^{23}$

For Candida species, the mean MIC of terbinafine, itraconazole, fluconazole and griseofulvin was $0.39 \mu \mathrm{g} / \mathrm{mL}, \quad 0.46 \mu \mathrm{g} / \mathrm{mL}, \quad 31.27 \mu \mathrm{g} / \mathrm{mL}$ and $4 \mu \mathrm{g} /$ $\mathrm{mL}$ respectively. For Candida albicans, the GM of terbinafine, itraconazole, fluconazole and griseofulvin were $0.43 \mu \mathrm{g} / \mathrm{mL}, 0.54 \mu \mathrm{g} / \mathrm{mL}, 26.3 \mu \mathrm{g} / \mathrm{mL}$ and $4 \mu \mathrm{g} /$ $\mathrm{mL}$ respectively. For Non albicans candida, the GM of terbinafine, itraconazole, fluconazole and griseofulvin were $0.35 \mu \mathrm{g} / \mathrm{mL}, 0.55 \mu \mathrm{g} / \mathrm{mL}, 40 \mu \mathrm{g} / \mathrm{mL}$ and $>4 \mu \mathrm{g} /$ $\mathrm{mL}$ respectively. In a past study by Bueno et al, in case of $C$. albicans, the mean MIC for terbinafine, itraconazole and fluconazole were $0.69 \mu \mathrm{g} / \mathrm{mL}$, $0.097 \mu \mathrm{g} / \mathrm{mL}$ and $0.65 \mu \mathrm{g} / \mathrm{mL}$, respectively. ${ }^{24}$ While in case of C.parapsilosis, the mean MIC for terbinafine, itraconazole and fluconazole were $0.67 \mu \mathrm{g} / \mathrm{mL}$, $0.083 \mu \mathrm{g} / \mathrm{mL}$ and $0.98 \mu \mathrm{g} / \mathrm{mL}$, respectively. This higher mean MIC for candida species to fluconazole in our study can be due to emerging or growing resistance to fluconazole causing higher dose requirement. According to Ryder et al, the MIC50 of terbinafine for C. albicans and C. parapsilosis was $1 \mu \mathrm{g} / \mathrm{mL}$ and $0.06 \mu \mathrm{g} / \mathrm{mL}$, respectively. The MIC50 of fluconazole for C. albicans and C.parapsilosis was $0.5 \mu \mathrm{g} / \mathrm{mL}$ and $1 \mu \mathrm{g} / \mathrm{mL}$, respectively. ${ }^{25}$ In our study, slight high MICs obtained for Candida species with terbinafine are consistent with the differential fungistatic or fungicidal activity that has been previously reported by Gupta et al, therefore, we would recommend cautious use of terbinafine against different Candida strains. ${ }^{26}$ Ghannoum et al also observed a wide range in the MICs of the non-dermatophyte molds and yeasts, with Itraconazole and terbinafine showed greater activity against the filamentous molds and fluconazole higher antifungal activity against the yeasts. ${ }^{21}$ However, in our study mean MIC for fluconazole was higher both for filamentous fungi and yeasts as compared to other anti - fungal, that can be attributed to the fact that fluconazole being most commonly used and misused antifungal drug for the fungal infection, making genera resistant to them or requirement of higher dose of fluconazole for Non dermatophytic fungi. This result is in concordance to Zisova et al, who recommended that higher weekly doses (300-450 mg) of fluconazole is required when the offending agent is a NDM.

Various interlaboratory variation in antifungal MIC data can be due to the batch of growth medium, performance of the medium from different manufacturers, the $\mathrm{pH}$ and even the solvent used to prepare antifungal stock solutions, in addition to longestablished sources of variation such as inoculum size, incubation time, end-point criterion and, in the case of azole antifungals, the 'trailing growth' effect. ${ }^{28-}$ ${ }^{33}$ Laboratories in USA prefers the use of microdilution plates with U-bottomed wells for antifungal susceptibility testing, and method M27-A stipulates the use of such plates, yet in Europe flat-bottomed wells are the commonly used. There are various unpublished anecdotes of, like the use of $\mathrm{CO}_{2}$ versus air incubators and sealed versus unsealed microdilution plates, according to judgement, availability or laboratory habit, indicate further possible sources of variation in test outcomes.

Shortcoming of the study was that Differentiation in species for non - dermatophytic fungi was not done in our study, it plays an important role in antifungal susceptibility pattern of non-dermatophyte. Different species in same genus show different pattern of antifungal susceptibility as well as different pattern of prevalence with varied geographical areas. Higher dilutions of the drugs are required to find the Minimum inhibitory concentration of drugs against those isolates that showed in vitro resistance to drug. 
MIC breakpoints have not yet been established for onychomycosis, but it still remains unclear whether the in vitro activity of antifungal drugs is predictive of the clinical outcome.

\section{Conclusion}

Fusarium species were the most common nondermatophyte isolated followed by Aspergillus species. Maximum sensitivity for overall non dermatophytes were seen with Itraconazole > Terbinafine > Fluconazole $>$ Griseofulvin. Fusarium species was most sensitive to terbinafine and least to griseofulvin. Aspergillus species was most sensitive to itraconazole and least to griseofulvin. Candida species was most sensitive to fluconazole and resistant to griseofulvin. Rhizopus species and Neoscytalidium species were most sensitive to terbinafine and resistant to fluconazole species. Penicillium species was most sensitive to

\section{References}

1. Sageerabanoo, Malini A, Oudeacoumar $P$, Udayashankar C. Onychomycosis due to Trichosporon mucoides. Indian J Dermatol Venereol Leprol 2011;77:76-7. https://doi. org/10.4103/0378-6323.75001

2. Ahuja S, Malhotra S, Charoo H. Etiological agents of onychomycosis from a tertiary care hospital in central Delhi, India. Indian J Fundam Appl Life Sci 2011;1:11-4.

3. Kaur R, Kashyap B, Bhalla P. Onychomycosisepidemiology, diagnosis and management. Indian J Med Microbiol 2008;26:108-16. https:// doi.org/10.4103/0255-0857.40522

4. Gupta AK, Ryder JE, Baran R, Summerbell RC. Non-dermatophyte onychomycosis. Dermatol Clin. 2003 Apr;21(2):257-68. https://doi. org/10.1016/S0733-8635(02)00086-4

5. Arikan S. Current status of antifungal susceptibility testing methods. Med. Mycol 2007 (Nov); 45: 569-87. https://doi. org/10.1080/13693780701436794

6. Clinical and Laboratory Standards Institute. M27-A3: Reference Method for Broth Dilution Antifungal Susceptibility Testing of Yeasts; Approved Standard-3rd ed.; CLSI: Wayne, PA, USA, 2008.

7. Clinical and Laboratory Standards Institute. M38-A2: Reference Method for Broth Dilution Antifungal Susceptibility Testing of Filamentous terbinafine and griseofulvin and least to fluconazole. Alternaria species was sensitive to all the four drugs. Bipolaris species was most sensitive to terbinafine and itraconazole, and least to fluconazole and griseofulvin. Curvularia species was most sensitive to terbinafine and least sensitive to fluconazole.

Due to the paucity of the literature about the MIC for individual antifungal drugs for non-dermatophytes, it was difficult to standardise the MIC of various drugs for non - dermatophytes. Further studies are required in this field to standardise the fungal susceptibility procedure, to prevent the variation in testing procedure hence causing variation in the results. The standardised technique will help which further reduce the development of resistance to various antifungal agents by initiation of target - centered treatment.

Conflict of interest: None

Financial disclosure: None declared.

Fungi; Approved Standard-2nd ed.; CLSI: Wayne, PA, USA, 2008.

8. Kaur R, Panda SP, Khan S. Non dermatophytic molds causing onychomycosis: a rising trend in North India. Int J Community Med Public Health 2017 Dec;4(12):4532-7. https://doi. org/10.18203/2394-6040.ijcmph20175325

9. Grover S, Roy P. Clinico-mycological profile of Superficial Mycosis in a Hospital in NorthEast India. MJAFI 2003;59:114-6. https://doi. org/10.1016/S0377-1237(03)80053-9

10. Lone R, Showkat HI, Bashir D, Khursheed S, Sarmast AH. Clinico-Mycological Pattern of Onychomycosis. A single center one year study in Kashmir-North India. Eur J Gen Med 2013;10(3):150-3. https://doi.org/10.29333/ ejgm/82247

11. Lakshmanan A, Ganeshkumar P, Raam Mohan S, Hemamalini M, Madhavan R. Epidemiological and clinical pattern of dermatomycoses in rural India. Indian J Med Microbiol 2015;33 (Supplement 1):34-6. https://doi.org/10.4103/02550857.150922

12. Kaur R, Kashyap B, Bhalla P. A five year survey of onychomycosis in New Delhi, India: epidemiological and laboratory aspects. Indian J Dermatolol 2007;52:39-42. https://doi. org/10.4103/0019-5154.31923

13. Jesudanam TM, Rao GR, Lakshmi DJ, Kumari GR. Onychomycosis: A significant medical problem. Indian J Dermatol Venereol Leprol 2002;68:3269. 
14. Attal RO, Chaudhary RA, Deotale VS, Jain SP: A clinicomycological study of onychomychosis in a rural hospital in Central India. Int. J Res Med Sci 2015 May;3(5):1131-7. https://doi. org/10.5455/2320-6012.ijrms20150519

15. Bassiri-Jahromi S, Khaksar A. Nondermatophytic moulds as a causative agent of onychomycosis in Tehran. Indian J Dermatol 2010;55:140. https:// doi.org/10.4103/0019-5154.62743

16. Adhikari L, Gupta AD, Pal R, Singh T. Clinicoetiologic co-relates of onychomycosis in Sikkim. Indian J Pathol Microbiol 2009; 52: 194-7. https://doi.org/10.4103/0377-4929.48915

17. Biradar SK, Tazeen A. Spectrum of Fungi causing Onychomycosis in a Tertiary care Hospital in North East Karnataka. International Journal of Medical Microbiology and Tropical Disease 2016;2(4):153-6.

18. Gupta AK, Kohli $\mathrm{Y}$, Batra R. In vitro activities of posaconazole, ravuconazole, terbinafine, itraconazole and fluconazole against dermatophyte, yeast and non-dermatophyte species. Med Mycol 2005;43:179-85. https://doi. org/10.1080/13693780410001731583

19. Biancalana FS, Lyra L, Schreiber AZ2011. In vitro evaluation of the type of interaction obtained by the combination of terbinafine and itraconazole, voriconazole, or amphotericin B against dematiaceous molds. Antimicrob. Agents Chemother 55:4485-7. https://doi.org/10.1128/ AAC.01015-10

20. Guillermo Garcia-Effron, Alicia Gomez-Lopez, Emilia Mellado, Araceli Monzon, Juan L. Rodriguez-Tudela, Manuel Cuenca-Estrella. In vitro activity of terbinafine against medically important non-dermatophyte species of filamentous fungi. J Antimicrob Chemother 2004:53;6;1086-89. https://doi.org/10.1093/ $\mathrm{jac} / \mathrm{dkh} 228$

21. Ghannoum MQ, Hajjeh RA, Scher R, Konnikov $N$, Gupta AK, Summerbell R, et al. A largescale North American study of fungal isolates from nails: The frequency of onychomycosis, fungal distribution and antifungal susceptibility patterns. J Am Acad Dermatol 2000;43:641-8. https://doi.org/10.1067/mjd.2000.107754

22. Alastruey Izquierdo, Ana \& Cuenca-Estrella, Manuel \& Monzón, Araceli \& Mellado, Emilia \&Rodriguez-Tudela, Juan. Antifungal susceptibility profile of clinical Fusarium spp. isolates identified by molecular methods. J Antimicrob Chemother 2008;61: 805-9. https:// doi.org/10.1093/jac/dkn022
23. Lalitha $P$, Shapiro $B L$, Srinivasan $M$, Prajna NV, Acharya NR, Fothergil AW, et al. Antimicrobial susceptibility of Fusarium, Aspergillus, and other filamentous fungi isolated from keratitis. Arch Ophthalmol 2007;125:789-93. https://doi. org/10.1001/archopht.125.6.789

24. Bueno JG, Martinez C, Zapata B, Sanclemente G, Gallego M, Mesa AC. In vitro activity of fluconazole, itraconazole, voriconazole and terbinafine against fungi causing onychomycosis. Clin Exp Dermatol 2010;35:658-63. https://doi. org/10.1111/j.1365-2230.2009.03698.x

25. Ryder NS, Wagner S, Leitner I. In vitro activities of terbinafine against cutaneous isolates of Candida albicans and other pathogenic yeasts. Antimicrob. Agents Chemother 1998;42:105761. https://doi.org/10.1128/AAC.42.5.1057

26. Gupta AK, Jain HC, Lynde CW, Watteel GN and Summerbell RC. Prevalence and epidemiology of unsuspected onychomycosis in patients visiting dermatologists' offices in Ontario, Canada - a multicenter survey of 2001 patients. Int J Dermatol 1997;36:783-7. https://doi. org/10.1046/j.1365-4362.1997.00349.x

27. Zisova L. Fluconazole (Fungolon) in the treatment of onychomycoses. Folia Medica 2004; 46: 4749.

28. Lozano-Chiu, M, Nelson PW, Lancaster M., Pfaller, MA, Rex JH. Lot-to-lot variability of antibiotic medium 3 used for testing susceptibility of Candida isolates to amphotericin B. Journal of Clinical Microbiology 1997;35: 270-2. https:// doi.org/10.1128/JCM.35.1.270-272.1997

29. Rodriguez-Tudela JL, Arendrup MC, Barchiesi F, Bille J, Chryssanthou E, Cuenca-Estrella M, et al. EUCAST Definitive Document EDef 7.1: method for the determination of broth dilution MICs of antifungal agents for fermentative yeasts. Clin Microbiol Infect 2008;14:398-405. https://doi. org/10.1111/j.1469-0691.2007.01935.x

30. Marr KA, Rustad TR, Rex JH, White TC. The trailing end point phenotype in antifungal susceptibility testing is $\mathrm{pH}$ dependent. Antimicrob Agents Chemother 1999;43,1383-6. https://doi. org/10.1128/AAC.43.6.1383

31. Galgiani JN, Lewis ML. In vitro studies of activities of the antifungal triazoles SCH56592 and itraconazole against Candida albicans, Cryptococcus neoformans, and other pathogenic yeasts. Antimicrob Agents Chemother 1997;41:180-3. https://doi.org/10.1128/ AAC.41.1.180 
32. Revankar SG, Kirkpatrick WR, McAtee RK., Fothergill AW, Redding SW, Rinaldi MG, et al. Interpretation of trailing endpoints in antifungal susceptibility testing by the National Committee for Clinical Laboratory Standards method. J Clin Microbiol 1998;36,153-6. https://doi. org/10.1128/JCM.36.1.153-156.1998
33. Pfaller MS, Rinaldi MG, Galgiani JN, Bartlett MS, Body BA, Espinel-Ingroff A, et al. Collaborative investigation of variables in susceptibility testing of yeasts. Antimicrob Agents Chemother 1990;34:1648-54. https://doi.org/10.1128/ AAC.34.9.1648 